\title{
Effect of E-64 Supplementation during In Vitro Maturation on the Developmental Competence of Bovine OPU-Derived Oocytes
}

\author{
Ahmed Z. Balboula 1,2,3 ${ }^{\mathbb{D}}$, Mansour Aboelenain ${ }^{3,4} \mathbb{D}^{\mathbb{D}}$, Miki Sakatani ${ }^{2,5}$, Ken-Ichi Yamanaka ${ }^{2,6}$, Hanako Bai ${ }^{7}$, \\ Takahiro Shirozu ${ }^{7}$, Manabu Kawahara ${ }^{7}$ D, Abd Elraouf O. Hegab ${ }^{3,8}$, Samy M. Zaabel ${ }^{3}$ \\ and Masashi Takahashi ${ }^{2,7,9, *}$
}

\section{check for}

updates

Citation: Balboula, A.Z.; Aboelenain,

M.; Sakatani, M.; Yamanaka, K.-I.; Bai,

H.; Shirozu, T.; Kawahara, M.; Hegab, A.E.O.; Zaabel, S.M.; Takahashi, M. Effect of E-64 Supplementation during In Vitro Maturation on the Developmental Competence of Bovine OPU-Derived Oocytes. Genes 2022, 13, 324. https://doi.org/ 10.3390 /genes 13020324

Academic Editor: Terje Raudsepp

Received: 18 January 2022

Accepted: 8 February 2022

Published: 10 February 2022

Publisher's Note: MDPI stays neutral with regard to jurisdictional claims in published maps and institutional affiliations.

Copyright: (C) 2022 by the authors. Licensee MDPI, Basel, Switzerland. This article is an open access article distributed under the terms and conditions of the Creative Commons Attribution (CC BY) license (https:// creativecommons.org/licenses/by/ $4.0 /)$.
1 Animal Sciences Research Center, University of Missouri, Columbia, MO 65211, USA; abalboula@missouri.edu

2 National Agricultural Research Center for Kyushu Okinawa Region, National Agriculture and Food Research Organization, Koshi, Kumamoto 861-1192, Japan; msaka@affrc.go.jp (M.S.); kyama@cc.saga-u.ac.jp (K.-I.Y.)

3 Theriogenology Department, Faculty of Veterinary Medicine, Mansoura University, Mansoura 35516, Egypt; mma247@dls.rutgers.edu (M.A.); abraoshe@yahoo.com (A.E.O.H.); samy.zaabel@yahoo.com (S.M.Z.)

4 Genetics Department, Rutgers University, 145 Bevier Rd., Piscataway, NJ 08854, USA

5 Institute of Livestock and Grassland Science, National Agriculture and Food Research Organization, Tochigi 329-2793, Japan

6 Faculty of Agriculture, Saga University, Honjo-machi, Saga 840-8502, Japan

7 Laboratory of Animal Genetics and Reproduction, Department of Animal Science, Research Faculty of Agriculture, Hokkaido University, Sapporo 060-8589, Japan; hbai@anim.agr.hokudai.ac.jp (H.B.); takahiro.shirozu@fujita-hu.ac.jp (T.S.); k-hara@anim.agr.hokudai.ac.jp (M.K.)

8 Department of Biology, Faculty of Science, Taif University, Taif 26571, Saudi Arabia

9 Research Faculty of Agriculture/Global Center for Food, Land and Water Resources, Hokkaido University, Sapporo 060-8589, Japan

* Correspondence: mmasashi@anim.agr.hokudai.ac.jp

Abstract: Recovery of bovine oocytes using the ovum pick-up (OPU) technique offers the advantage of rapid genetic improvement through propagation of desired genes from animals with high genetic qualities. However, the developmental competence of OPU-derived immature oocytes remains relatively poor. We previously found that cathepsin B gene expression and activity are increased in poor quality oocytes and embryos compared to good quality ones. In this study, we investigated the effect of E-64 (cathepsin B inhibitor) supplementation during in vitro maturation (IVM) on the developmental competence of OPU-derived immature oocytes and the quality of the produced blastocysts. Our results showed that supplementation of IVM medium with E-64 significantly improved the developmental competence of OPU-derived immature oocytes as evidenced by the significant increase of the blastocyst rate. Importantly, the presence of E-64 during IVM also significantly improved blastocyst quality by increasing the total cell number and decreasing the percentage of TUNEL positive cells. These results indicate that E-64 supplementation during IVM is a promising tool to improve the efficiency of OPU-IVF program by improving the developmental competence of OPU-derived immature oocytes.

Keywords: ovum pick-up; cathepsin B; E-64; in vitro maturation; developmental competence; bovine oocytes

\section{Introduction}

In the livestock industry, assisted reproductive technologies (ARTs) have been developed to improve the reproductive efficiency and the genetic properties of animals. Among ARTs, in vitro embryo production (IVEP) emerged as the most widely promising approach in the past decade. IVEP following the recovery of female gametes from slaughtered animals has the advantage to maximize the rapid expansion of animal population, obtain a 
large number of zygotes at a low cost, and improve the genetic quality of the produced embryos. However, one of the main limitations is the impossibility to repeat the recovery of oocytes from the animal of high genetic merit. Therefore, the recovery of cumulus oocyte complexes (COCs) from live animals using the ovum pick-up (OPU) technique overcomes this limitation and offers an alternative approach to produce a large number of offspring with respect to the potential oocyte population contained in the ovary [1].

The first ultrasound-guided transvaginal OPU in cows was performed in 1988 by Pieterse et al., followed by many attempts to improve its efficiency [2-6]. The effectiveness of OPU depends on the recovery rate, which is affected by several factors, such as hormonal super-stimulation of animals, needle type, puncture frequency, time of puncture within the estrous cycle, aspiration vacuum, and the operator's experience [7-11]. Despite all the progress that has been made in OPU technique, the percentage of in vitro produced blastocysts is still low $(\sim 25-35 \%)$ [12]. One of the primary reasons for the reduced rate of in vitro blastocyst production is the reduced quality and the lack of developmental competence of the recovered oocytes after fertilization [12]. Indeed, OPU-derived oocytes exhibit lower morphological quality when compared to those collected by aspiration from slaughterhouse ovaries [13]. For example, the average percentage of grade 1 oocytes per collection was $\sim 20 \%$ for OPU-derived COCs compared to $49 \%$ for COCs collected from slaughterhouse ovaries [12,13]. Therefore, improving the culture condition necessary to promote the quality and the developmental competence of OPU-derived COCs will be a prerequisite to improve the efficiency of OPU-IVF technology.

Apoptosis is considered one of the causes of impaired developmental competence of mammalian COCs [14-17]. Poor quality OPU-derived COCs have higher rates of apoptosis when compared to good quality COCs [18]. We previously demonstrated that cathepsin B (CTSB) apoptotic pathway is a marker of inferior quality COCs and inversely correlated with the developmental competence of bovine COCs and preimplantation embryos (day 2, 4 , and 7 embryos) [15]. Moreover, Ctsb gene expression was significantly higher in poor quality bovine embryos, compared to good quality embryos [19]. Accordingly, inhibition of CTSB activity using cell-permeable inhibitor (1-trans-Epoxysuccinyl-Leucylamido(4-guanidino) butane, E-64) improved the developmental competence of bovine oocytes and the quality of the produced blastocysts $[15,19,20]$. Given the poor quality and reduced developmental competence of OPU-derived oocytes, it is possible that manipulating the apoptotic pathway during in vitro maturation (IVM) using E-64 will be a promising strategy to improve the developmental rate and the quality of the OPU-derived blastocysts.

In the present study, we show that supplementation of IVM medium with E-64 can improve the developmental competence of OPU-derived immature oocytes. In addition, E-64 supplementation improves the quality of the produced blastocysts, at least partially, through down-regulating the apoptotic rate.

\section{Methods}

The study was carried out at the Kyushu-Okinawa Agricultural Research Center, NARO, Japan. All experiments were approved by the Animal Experimental Committee of Kyushu Okinawa Agricultural Research Center, NARO.

\subsection{Chemicals}

Unless otherwise specified, chemicals were purchased from Sigma-Aldrich (St. Louis, MO, USA).

\subsection{Post-Mortem COC Collection}

Pairs of ovaries from Japanese Black cows were obtained from a local slaughterhouse. The ovaries were then washed in sterile saline containing $100 \mathrm{IU} / \mathrm{mL}$ penicillin and $100 \mu \mathrm{g} / \mathrm{mL}$ streptomycin (Nacalai Tesque, Kyoto, Japan). COCs were aspirated from follicles with diameters ranging from 2 to $6 \mathrm{~mm}$ using a 19-gauge needle attached to a 10-mL syringe. 


\subsection{Transvaginal Ultrasound-Guided OPU}

Transvaginal ultrasound-guided OPU was performed weekly on 4-8 year-old, healthy, pluriparous Japanese Black cows, according to Pieterse et al. [10]. Donors were not hormonally treated before OPU. Sedation of the cow was achieved by an intramuscular injection of Xyladin (Celactal, Bayer Health care, Tokyo, Japan). Caudal epidural anesthesia was performed using procaine $\mathrm{HCl}$ (Kawasaki-Mitaka pharmaceuticals, Kanagawa, Japan) to prevent rectal contraction. The vulva and perineal regions were thoroughly cleaned. An electronic convex probe for veterinary use (UST-9109P- 7.5 MHz, ALOKA, Japan) was used. After retraction of the uterus, the right or left ovary was placed against the head of the transducer which had been inserted into the vagina adjacent to the cervix. All 2-6 mm visible follicles were punctured and aspirated at $90 \mathrm{mmHg}$ vacuum pressure. The antral follicles appeared as black round spots on the monitor of the scanner (HS-2000V, Honda electronics, Aichi, Japan), and the puncture needle (Cow ova vacuuming needle A-type, Misawa Medical Industry, Tokyo, Japan) was depicted by a white line. The diameter of the follicles was estimated by calibration on the monitor. The transducer was positioned so that the puncture line on the monitor transected the follicle to be punctured. When a follicle was positioned steadily on the puncture line, the needle was pushed through the vaginal wall until its tip became visible within the follicle. This was directly followed by aspiration of the follicular contents. After the needle had been withdrawn, it was flushed with ovum preservation medium using $5 \%$ fetal calf serum (FCS) containing lactated Ringer's solution (the same solution was used for ovum aspiration). All steps were done using controlled temperature tubes at $38.5^{\circ} \mathrm{C}$.

\subsection{In Vitro Maturation}

Bovine COCs were washed three times in tissue cultured medium-199 (TCM-199 (Gibco, Grand Island, NY, USA) enriched with 5\% FCS, follicle stimulating hormone (FSH, $0.02 \mathrm{IU} / \mathrm{mL}$; Denka, Kawasaki, Tokyo, Japan), estradiol-17 $\beta(1 \mu \mathrm{g} / \mathrm{mL})$, and gentamicin $(10 \mu \mathrm{g} / \mathrm{mL}$ ), followed by incubation in the same medium (fifty COCs $/ 500 \mu \mathrm{L}$ medium volume) under mineral oil at $38.5^{\circ} \mathrm{C}$ for $22 \mathrm{~h}$ in a humidified atmosphere of $5 \% \mathrm{CO}_{2}$ in air.

E-64 (E3132) was dissolved in phosphate-buffered saline (PBS) and then added to TCM-199 medium to a final concentration of $1 \mu \mathrm{M}$. The final concentration of E-64 was selected based on our previous publications $[14,15,21,22]$

\subsection{In Vitro Fertilization}

Two frozen semen straws (from fertility-proven bulls) were thawed in warm water $\left(37^{\circ} \mathrm{C}\right)$ for $20 \mathrm{~s}$. Spermatozoa were then washed by centrifugation in $90 \%(v / v)$ Percoll solution (GE healthcare bio-sciences AB, Uppsala, Sweden) at $800 \times g$ for $10 \mathrm{~min}$. The supernatant was discarded and the pellet was then diluted with IVF-100 solution (Research institute for the functional peptides, Yamagata, Japan) prior to further centrifugation at $800 \times g$ for $5 \mathrm{~min}$. The spermatozoa pellet was then diluted again with IVF-100 to prepare the final concentration of sperm cells at $5-10 \times 10^{6} / \mathrm{mL}$.

The matured COCs were washed three times with IVF-100 followed by incubation in sperm cells suspension ( 20 oocytes $/ 100 \mu \mathrm{L}$ drop) covered with mineral oil. To allow fertilization, COCs were co-incubated with spermatozoa for $6 \mathrm{~h}$ at $38.5^{\circ} \mathrm{C}$ in a humidified atmosphere of $5 \% \mathrm{CO}_{2}$ in air according to [14,23-26].

\subsection{In Vitro Culture}

The fertilized oocytes were denuded mechanically by pipetting in Charles Rosenkran's 1 amino acid (CR1aa) medium [27] containing 5\% FCS and supplemented with essential and non-essential amino acids. Presumptive zygotes were then transferred into micro-drops of CR1aa supplemented with $5 \%$ FCS (20-30 zygotes $/ 50 \mu \mathrm{L}$ medium), followed by culturing for 7 days in a humidified atmosphere of $5 \% \mathrm{O}_{2}, 5 \% \mathrm{CO}_{2}$ and $90 \% \mathrm{~N}_{2}$ at $38.5^{\circ} \mathrm{C}$. Cleavage and blastocyst rates were evaluated on days 2 and 7 , respectively. 


\subsection{Terminal Deoxynucleotidyl Transferase Fluorescein-dUTP Nick End Labeling (TUNEL)}

To evaluate the apoptotic status of the produced blastocysts, a TUNEL assay kit (In Situ Cell Death Detection Kit, Roche applied science, USA) was employed according to Balboula et al. [14]. Blastocysts were fixed in $4 \%(w / v)$ paraformaldehyde solution ( $\mathrm{pH} 7.4)$ for $30 \mathrm{~min}$ followed by a brief washing in PBS containing $3 \mathrm{mg} / \mathrm{mL}$ PVP. The blastocysts were then permeabilized in PBS with $0.5 \%$ Triton $X$ for 20 min followed by washing (twice/10 min) in PBS with $3 \mathrm{mg} / \mathrm{mL}$ PVP. To label the fragmented DNA ends, blastocysts were incubated with fluorescein-dUTP for $60 \mathrm{~min}$ at $37^{\circ} \mathrm{C}$. The incubated blastocysts were washed three times in PBS with $3 \mathrm{mg} / \mathrm{mL}$ PVP for 5 min each, prior to mounting onto glass slides using DAPI (Vectashield with DAPI, Vector laboratories, Burlingame, CA, USA). Fluorescence was detected on a fluorescent microscope (TE-300, Nikon, Tokyo, Japan). To detect the fluorescence of fragmented DNA ends, excitation filter of $488 \mathrm{~nm}$ was used. Excitation filter of $365 \mathrm{~nm}$ was used to observe the DNA. Counting of total cells (marked by DAPI) or TUNEL positive cells was performed manually using Image J analysis software (NIH, Bethesda, MD, USA).

\subsection{Statistical Analysis}

Each experiment was replicated at least three times. The data were expressed as means \pm SEM. The statistical significance of differences was analyzed by Student $t$-test using Prism GraphPad Software (La Jolla, CA, USA). The differences of $p<0.05$ were considered significant.

\section{Results and Discussion}

IVM is one of the most critical steps during IVEP, in which the oocytes acquire their developmental competence. We previously demonstrated that $C t s b$ gene expression and CTSB activity are significantly increased in poor quality mature COCs and embryos than good quality ones [15,19]. Accordingly, inhibiting CTSB activity during IVM, using E-64, significantly improved the developmental competence of bovine oocytes, most likely through regulating the apoptotic pathway [15]. OPU-derived immature COCs are notoriously prone to reduced quality [12,13], and because poor quality COCs exhibit higher rates of apoptosis, therefore, we hypothesized that CTSB regulation during IVM could be a promising tool to improve the developmental competence of OPU-derived immature oocytes. However, it is widely acknowledged that the potential of bovine embryos to develop to the blastocyst stage is highly affected by individual variations. To investigate whether CTSB inhibition during IVM has the potential to improve the developmental competence of oocytes, irrespective of individual variations, bovine ovaries were collected separately at the abattoir. Bovine COCs were aspirated from the ovaries of the same animal and then matured in vitro in the presence (E-64 group) or absence (control group) of $1 \mu \mathrm{M} \mathrm{E}-64$, whose efficiency to inhibit CTSB activity was previously reported $[14,15,20,28]$. After IVM, COCs were in vitro fertilized and cultured for 7 days. Consistent with our previous reports [14,15], inhibition of CTSB did not affect the cleavage rate (Figure 1A), but significantly improved $(p<0.05)$ the blastocyst rate when compared to controls (Figure 1B). This improving effect of E-64 on the blastocyst rate $(\sim 47 \%)$ is comparable to several previous studies aimed to improve the efficiency of in vitro embryo production in cattle [29-31]. Average total cell number and the apoptotic status are considered efficient indicators for embryonic quality [32]. Inhibition of CTSB during IVM significantly increased $(p<0.001)$ the average total cell number of the resulting blastocysts (162.8 \pm 8.23$)$ when compared to controls (124.8 \pm 3.62 ; Figure 1C). Consistent with the improving effect of E-64 on the average total cell number, inhibition of CTSB activity during IVM resulted in a significant decrease $(p<0.001)$ in the percentage of TUNEL positive cells of day 7 blastocysts $(2.33 \pm 0.28 \%)$ when compared to blastocysts produced from oocytes matured in E-64 free medium (Figure 1D; $6.62 \pm 0.56 \%$ ). The improving effect of CTSB inhibition, after excluding the genetic variation factor, suggests that CTSB inhibition could be a promising strategy to improve the developmental competence of bovine oocytes recovered from live animals using OPU technique. 
A

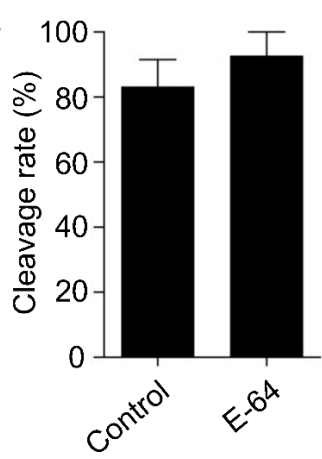

C

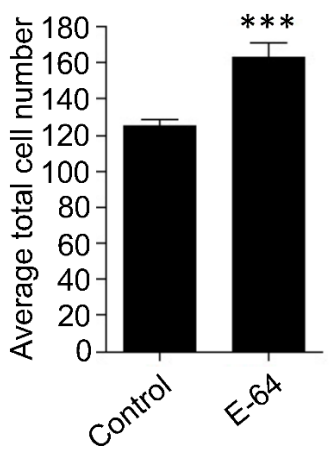

B

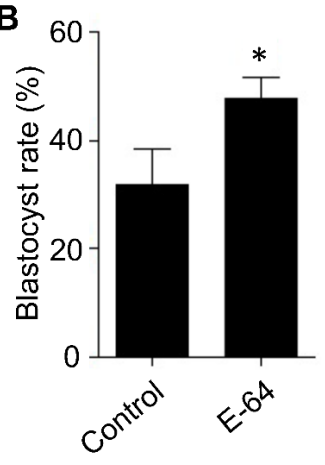

D

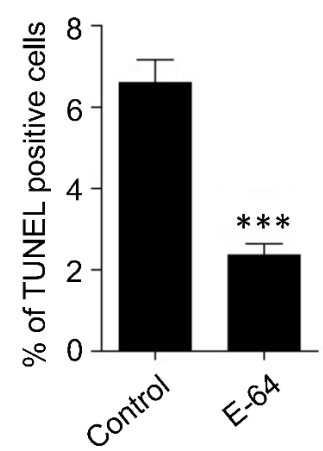

Figure 1. Effect of E-64 supplementation during in vitro maturation on the developmental rate and the quality of preimplantation embryos. Bovine COCs were collected separately from slaughterhouse ovaries of the same animal followed by in vitro maturation in the presence or absence of $1 \mu \mathrm{M}$ of E-64. After in vitro fertilization, presumptive zygotes were cultured for 7 days. Cleavage (A) and blastocyst (B) rates were observed on days 2 and 7, respectively. Total number of oocytes used is 166 . Total cell number of day 7 blastocysts was counted with DAPI (C). The apoptotic status of day 7 blastocysts was detected by TUNEL staining (D). Total number of embryos used is 44 . The experiments were carried out at least three times. The data are expressed as mean \pm SEM. Values with asterisks vary significantly, ${ }^{*} p<0.05,{ }^{* * *} p<0.001$.

To investigate the effect of CTSB inhibition on the developmental competence of OPU-derived immature oocytes, bovine COCs were recovered from live animals using transvaginal ultrasound-guided OPU technique followed by inhibition of CTSB activity during IVM. To this end, the recovered COCs were randomly distributed and in vitro matured in the presence (E-64 group) or absence (control group) of $1 \mu \mathrm{M} \mathrm{E}-64$ followed by fertilization and culture for 7 days to assess cleavage and blastocyst rates. Importantly, the addition of $1 \mu \mathrm{M}$ E-64 to the maturation medium improved the developmental rate (Figure 2A,C), as evidenced by the significant increase of the blastocyst rate $(p<0.05)$. On the other hand, no significant difference was observed regarding the cleavage rate (Figure 2A,B). In addition, inhibition of CTSB improved the quality of bovine blastocysts produced from OPU-derived immature oocytes. The total cell number of day 7 blastocysts produced from E-64-treated oocytes $(147.86 \pm 9.9)$ was significantly higher $(p<0.01)$ than that in the control group (Figure 3A,B; $116.38 \pm 5.5$ ). Moreover, supplementation of the IVM medium with E-64 significantly decreased the percentage of TUNEL positive cells in the produced blastocysts (Figure $3 \mathrm{~A}, \mathrm{C} ; 2.98 \pm 0.5 \% ; p<0.001$ ) when compared to controls $(8.45 \pm 1.2 \%)$. To our knowledge, this is the first study that aimed to investigate the effect of CTSB inhibition on the developmental competence of OPU-derived immature oocytes in mammals. Our results of the significant increase of the developmental competence of bovine oocytes after CTSB inhibition during IVM clearly show that E-64 might be an important supplement during IVM of bovine oocytes recovered using OPU technique. 
A
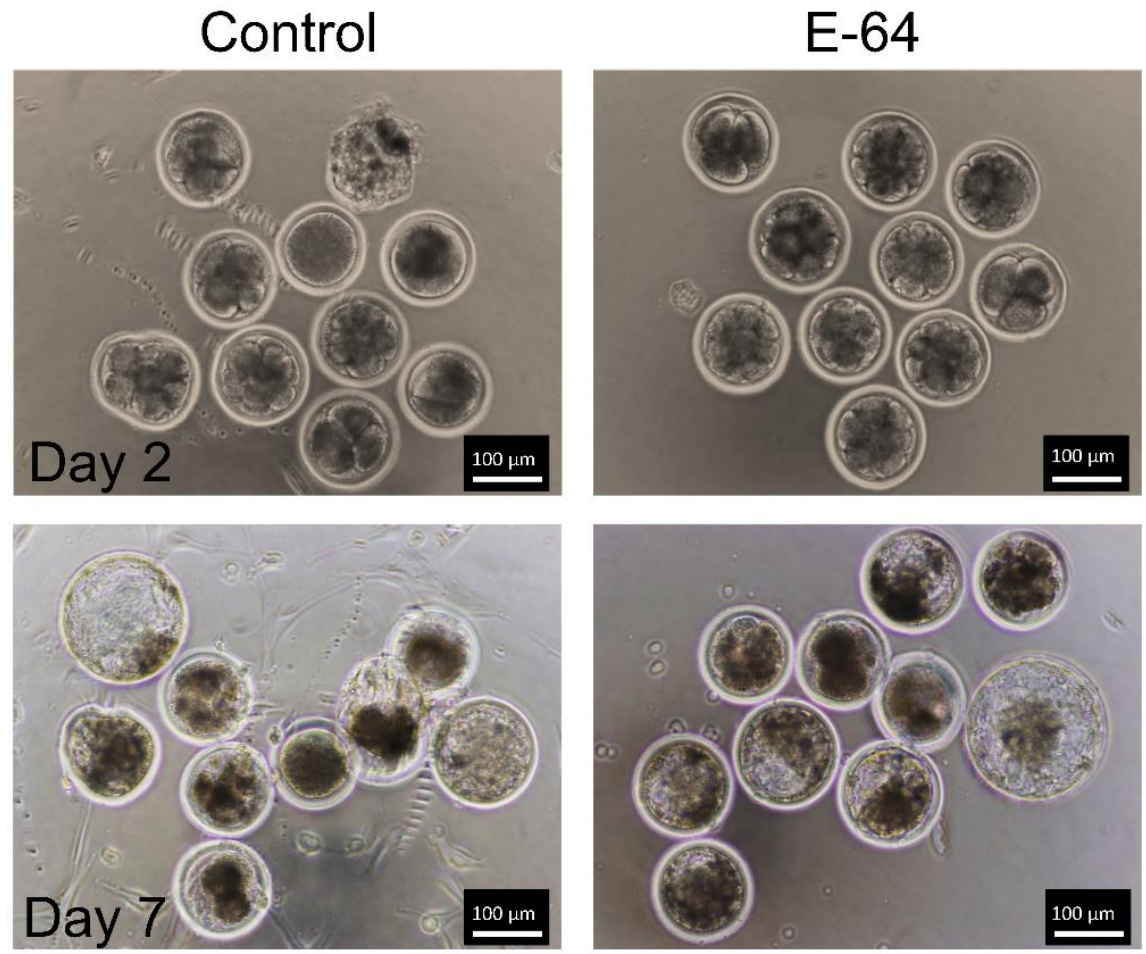

B
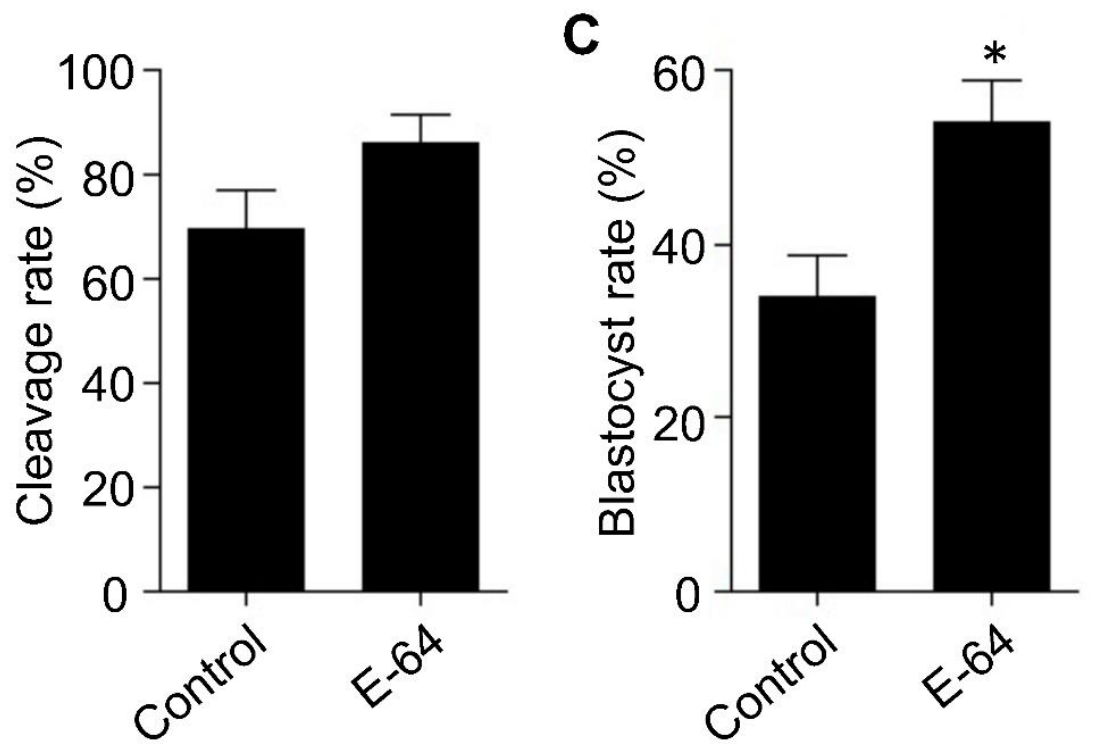

Figure 2. Effect of E-64 supplementation during in vitro maturation on the developmental competence of ovum pick-up-derived immature oocytes. Bovine COCs were recovered from live animals using ultrasound-guided transvaginal ovum pick-up technique. Recovered COCs were in vitro matured in the presence or absence of $1 \mu \mathrm{M}$ of E-64. After in vitro fertilization, putative zygotes were cultured for 7 days. (A) Cleavage rate was evaluated on day 2 while the blastocyst rate was evaluated on day 7. Shown are representative images. (B) Quantifications of the cleavage rate. (C) Quantifications of the blastocyst rate. Total number of oocytes used is 98. The experiments were carried out five times. The data are expressed as mean \pm SEM; Student's $t$-test was used to analyze the data. Values with asterisks vary significantly, ${ }^{*} p<0.05$. 
A
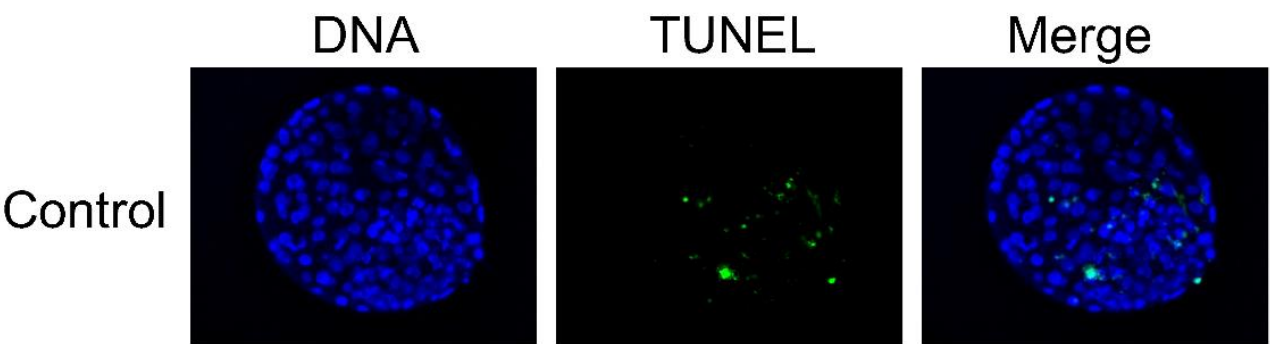

E-64
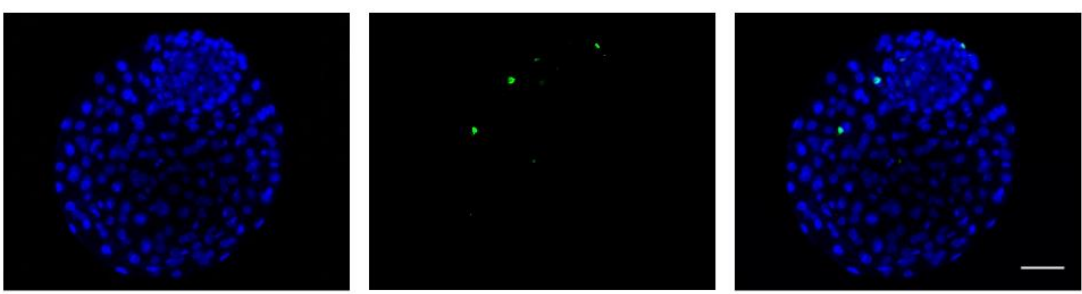

B

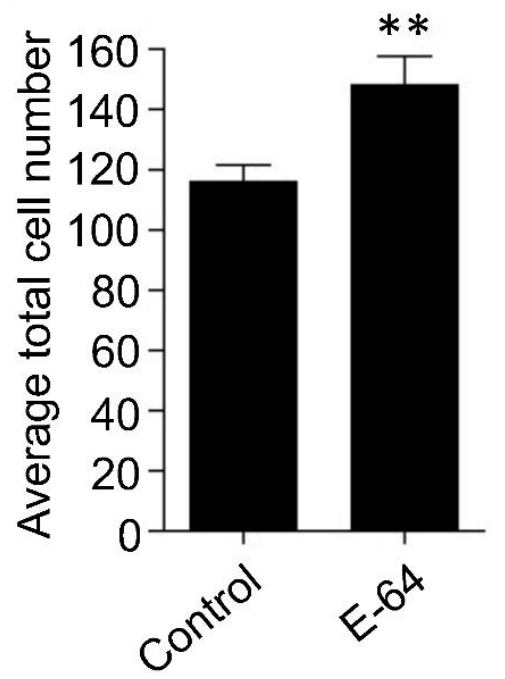

C

Figure 3. Effect of E-64 supplementation during in vitro maturation on the quality of preimplantation embryos. Bovine COCs were recovered from live animals using ultrasound-guided transvaginal ovum pick-up technique. Recovered COCs were in vitro matured in the presence or absence of $1 \mu \mathrm{M}$ of E-64 followed by IVF and culture. (A) Day 7 blastocysts were examined using TUNEL staining (green) to assess the apoptotic status and DAPI (blue) to assess the total cell number. Shown are representative images. (B) Quantification of the average total cell number. (C) Quantification of the percentage of TUNEL positive cells. Total number of oocytes used is 46 . The experiments were carried out three times. The data are expressed as mean \pm SEM; Student's $t$-test was used to analyze the data. Values with asterisks vary significantly, ${ }^{* *} p<0.01,{ }^{* * *} p<0.001$.

OPU-derived COCs are notoriously prone to reduced quality [12,13]. This reduced quality might be attributed to the inappropriate vacuum pressure and needle characteristics, as well as environmental stress associated with OPU procedures and transportation $[13,33,34]$. Interestingly, under stress conditions, active CTSB is leaked from damaged lysosomes. Leaked CTSB protease can lead to mitochondrial membrane damage with subsequent activation of caspase 3 and initiation of the apoptotic pathway [35-37]. We previously demonstrated that CTSB activity is negatively correlated with the quality of bovine oocytes and preimplantation embryos. CTSB activity is significantly increased in poor morphological quality oocytes and embryos when compared to those with good quality $[14,19]$. Given that OPU-derived oocytes have a relatively poor quality with high 
rates of apoptosis $[13,18]$, it is plausible that E-64 enhanced the developmental rate and the quality of bovine COCs by regulating the apoptotic pathway (Figure 4). A limitation of this study is that we used once-weekly OPU protocol that can allow for the development of dominant follicles which might affect the quality and stimulate apoptosis in oocytes within subordinate follicles. It will be interesting to investigate whether CTSB inhibition improves the quality of oocytes recovered by hormonal stimulation or twice-weekly OPU protocol.

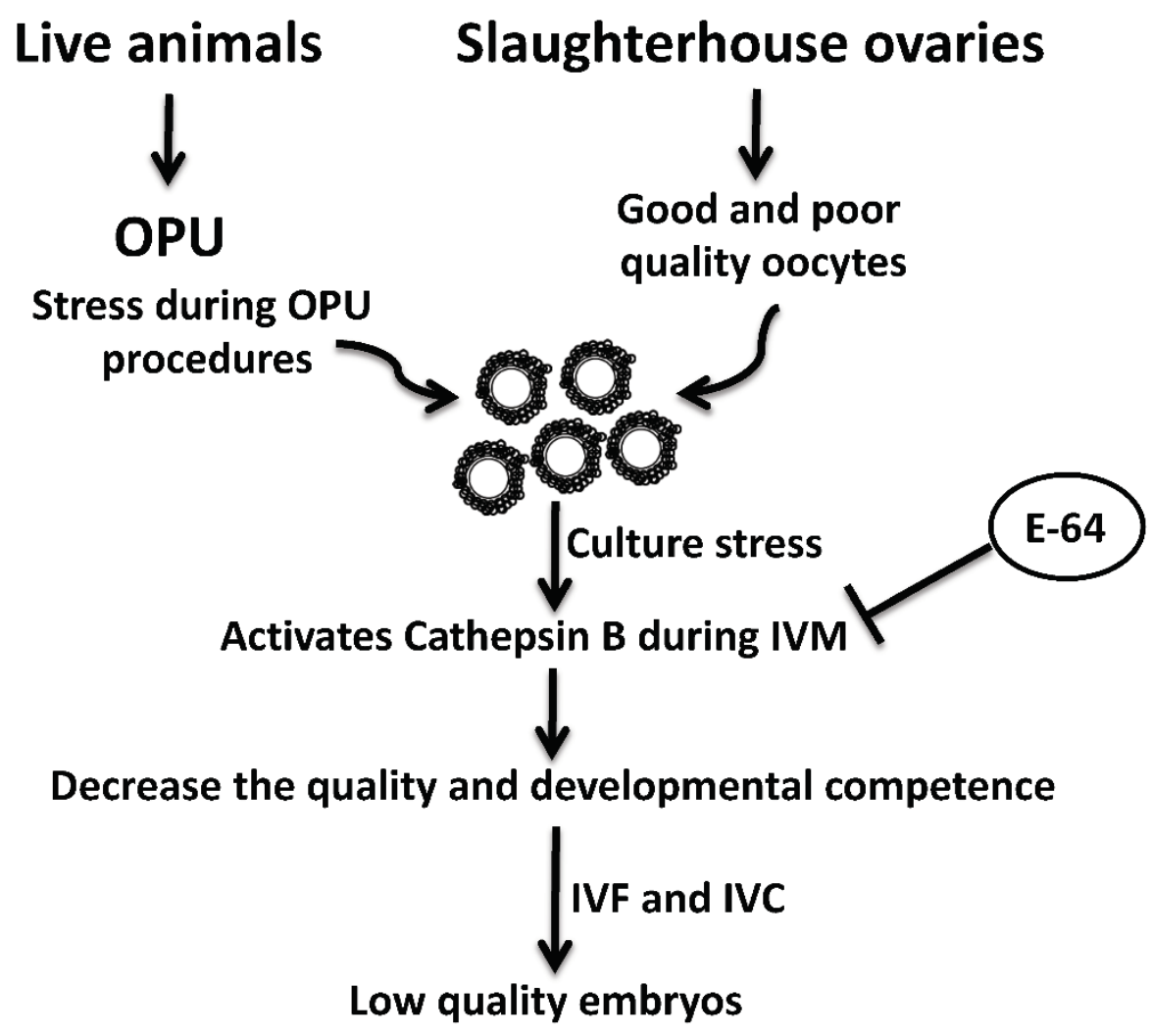

Figure 4. Schematic diagram of the role of cathepsin B and its inhibition by E-64 on the developmental competence and quality of bovine oocytes recovered by ultrasound-guided ovum pick-up technique.

\section{Conclusions}

Our findings indicate that CTSB inhibition is a promising strategy to improve the efficiency of OPU-IVF program by improving the quality and developmental competence of OPU-derived immature oocytes.

Author Contributions: A.Z.B. and M.T. designed and carried out the experiments. A.Z.B. and M.A. analyzed the results. A.Z.B., M.A., M.S., K.-I.Y., H.B., T.S., M.K., S.M.Z., A.E.O.H. and M.T. wrote and revised the manuscript. All authors have read and agreed to the published version of the manuscript.

Funding: This Research was supported by Grant-Aid for Scientific Research from JSPS (KAKENHI, 24580439) and by the Cooperative Research Program for Agriculture Science \& Technology Development (RDA PJ01029305). AZB was supported by a JSPS fund (P15400), Japan.

Institutional Review Board Statement: Not applicable.

Informed Consent Statement: Not applicable.

Data Availability Statement: All data generated or analyzed during this study are included in this published article.

Acknowledgments: The authors thank E. Kawano, Teramoto and Ogata for assistance of research. The authors also thank Kumamoto Meat Trading Center and Kumamoto prefectural Meat Inspection Office for collecting bovine ovaries. The authors thank Kathy Craighead, the University of Missouri, USA, for English language editing the manuscript. 
Conflicts of Interest: The authors declare no conflict of interest.

$\begin{array}{ll}\text { Abbreviations } \\ \text { ARTs } & \text { Assisted reproductive technologies } \\ \text { IVEP } & \text { In vitro embryo production } \\ \text { COCs } & \text { Cumulus oocyte complexes } \\ \text { OPU } & \text { Ovum pick-up } \\ \text { CTSB } & \text { Cathepsin B } \\ \text { IVM } & \text { In vitro maturation } \\ \text { E-64 } & \text { (l-trans-Epoxysuccinyl-Leucylamido-(4-guanidino) butane) } \\ \text { FCS } & \text { Fetal calf serum } \\ \text { FSH } & \text { Follicle stimulating hormone } \\ \text { TCM-199 } & \text { Tissue cultured medium-199 } \\ \text { PBS } & \text { Phosphate-buffered saline } \\ \text { CR1aa } & \text { Charles Rosenkran's 1 amino acid } \\ \text { TUNEL } & \text { Terminal deoxynucleotidyl transferase fluorescein-dUTP nick end labelling }\end{array}$

\section{References}

1. Boni, R. Ovum pick-up in cattle: A 25 yr retrospective analysis. Anim. Reprod. 2012, 9, 362-369.

2. Pieterse, M.C.; Kappen, K.A.; Kruip, T.A.; Taverne, M.A. Aspiration of bovine oocytes during transvaginal ultrasound scanning of the ovaries. Theriogenology 1988, 30, 751-762. [CrossRef]

3. Van der Schans, A.; Van der Westerlaken, A.J.; De Wit, A.A.; Eyestone, W.H.; DeBoer, H. Ultrasound guided transvaginal collection of oocytes in cow. Theriogenology 1991, 35, 288. [CrossRef]

4. Kruip, T.A.; Boni, R.; Wurth, Y.A.; Roelofsen, M.W.; Pieterse, M.C. Potential use of ovum pick-up for embryo production and breeding in cattle. Theriogenology 1994, 42, 675-684. [CrossRef]

5. Gibbons, J.R.; Krisher, R.L.; Carlin, S.K.; Pearson, R.E.; Gwazdauskas, F.C. In vitro embryo production after microinjection and ovarian dynamics following transvaginal follicular oocyte aspiration. Theriogenology 1995, 43, 1129-1139. [CrossRef]

6. Galli, C.; Crotti, G.; Notari, C.; Turini, P.; Duchi, R.; Lazzari, G. Embryo production by ovum pick up from live donors. Theriogenology 2001, 55, 1341-1357. [CrossRef]

7. Garcia, A.; Salaheddine, M. Effects of repeated ultrasound-guided transvaginal follicular aspiration on bovine oocyte recovery and subsequent follicular development. Theriogenology 1998, 50, 575-585. [CrossRef]

8. Hendriksen, P.J.; Steenweg, W.N.; Harkema, J.C.; Merton, J.S.; Bevers, M.M.; Vos, P.L.; Dieleman, S.J. Effect of different stages of the follicular wave on in vitro developmental competence of bovine oocytes. Theriogenology 2004, 61, 909-920. [CrossRef]

9. Bols, P.E.; Van Soom, A.; Ysebaert, M.T.; Vandenheede, J.M.; de Kruif, A. Effects of aspiration vacuum and needle diameter on cumulus oocyte complex morphology and developmental capacity of bovine oocytes. Theriogenology 1996, 45, 1001-1014. [CrossRef]

10. Pieterse, M.C.; Vos, P.L.; Kruip, T.A.; Wurth, Y.A.; van Beneden, T.H.; Willemse, A.H.; Taverne, M.A.M. Transvaginal ultrasound guided follicular aspiration of bovine oocytes. Theriogenology 1991, 35, 857-862. [CrossRef]

11. Bols, P.E.; Ysebaert, M.T.; Lein, A.; Coryn, M.; Van Soom, A.; de Kruif, A. Effects of long-term treatment with bovine somatotropin on follicular dynamics and subsequent oocyte and blastocyst yield in an OPU-IVF program. Theriogenology 1998, 49, 983-995. [CrossRef]

12. Deb, G.K.; Jin, J.I.; Kwon, T.H.; Choi, B.H.; Bang, J.I.; Dey, S.R.; Cho, I.R.; Kong, I.K. Improved blastocyst development of single cow OPU-derived presumptive zygotes by group culture with agarose-embedded helper embryos. Reprod. Biol. Endocrinol. RBEE 2011, 9, 121.

13. Mullaart, E.; Verbrugge, A.; Aerts, B.; Merton, J.S. Optimization of the OPU procedure. In Proceedings of the 15th Meeting European Embryo Transfer Association, Lyon, France, 7-8 September 1999; p. 216.

14. Balboula, A.Z.; Yamanaka, K.; Sakatani, M.; Kawahara, M.; Hegab, A.O.; Zaabel, S.M.; Takahashi, M. Cathepsin B activity has a crucial role in the developmental competence of bovine cumulus-oocyte complexes exposed to heat shock during in vitro maturation. Reproduction 2013, 146, 407-417. [CrossRef] [PubMed]

15. Balboula, A.Z.; Yamanaka, K.; Sakatani, M.; Hegab, A.O.; Zaabel, S.M.; Takahashi, M. Cathepsin B activity is related to the quality of bovine cumulus oocyte complexes and its inhibition can improve their developmental competence. Mol. Reprod. Dev. 2010, 77, 439-448. [CrossRef] [PubMed]

16. Roth, Z.; Hansen, P.J. Involvement of apoptosis in disruption of developmental competence of bovine oocytes by heat shock during maturation. Biol. Reprod. 2004, 71, 1898-1906. [CrossRef] [PubMed]

17. Kim, S.H.; Zhao, M.H.; Liang, S.; Cui, X.S.; Kim, N.H. Inhibition of cathepsin B activity reduces apoptosis by preventing cytochrome c release from mitochondria in porcine parthenotes. J. Reprod. Dev. 2015, 61, 261-268. [CrossRef] [PubMed] 
18. Saini, N.; Singh, M.K.; Shah, S.M.; Singh, K.P.; Kaushik, R.; Manik, R.S.; Singla, S.K.; Palta, P.; Chauhan, M.S. Developmental competence of different quality bovine oocytes retrieved through ovum pick-up following in vitro maturation and fertilization. Anim. Int. J. Anim. Biosci. 2015, 9, 1979-1985. [CrossRef]

19. Balboula, A.Z.; Yamanaka, K.; Sakatani, M.; Hegab, A.O.; Zaabel, S.M.; Takahashi, M. Intracellular cathepsin B activity is inversely correlated with the quality and developmental competence of bovine preimplantation embryos. Mol. Reprod. Dev. 2010, 77, 1031-1039. [CrossRef]

20. Bettegowda, A.; Patel, O.V.; Lee, K.B.; Park, K.E.; Salem, M.; Yao, J.; Ireland, J.J.; Smith, G.W. Identification of novel bovine cumulus cell molecular markers predictive of oocyte competence: Functional and diagnostic implications. Biol. Reprod. 2008, 79, 301-309. [CrossRef]

21. Balboula, A.Z.; Schindler, K.; Kotani, T.; Kawahara, M.; Takahashi, M. Vitrification-induced activation of lysosomal cathepsin B perturbs spindle assembly checkpoint function in mouse oocytes. Mol. Hum. Reprod. 2020, 26, 689-701. [CrossRef]

22. Li, J.; Balboula, A.Z.; Aboelenain, M.; Fujii, T.; Moriyasu, S.; Bai, H.; Kawahara, M.; Takahashi, M. Effect of autophagy induction and cathepsin B inhibition on developmental competence of poor quality bovine oocytes. J. Reprod. Dev. 2020, 66, 83-91. [CrossRef] [PubMed]

23. Iwasaki, W.; Yamanaka, K.; Sugiyama, D.; Teshima, Y.; Briones-Nagata, M.P.; Maeki, M.; Yamashita, K.; Takahashi, M.; Miyazaki, M. Simple separation of good quality bovine oocytes using a microfluidic device. Sci. Rep. 2018, 8, 14273. [CrossRef] [PubMed]

24. Momozawa, K. Usefulness of modified Medium RD as a chemically defined medium for in vitro maturation of bovine oocytes. Reprod. Med. Biol. 2020, 19, 365-371. [CrossRef]

25. Khatun, H.; Egashira, J.; Sakatani, M.; Takenouchi, N.; Tatemoto, H.; Wada, Y.; Yamanaka, K.I. Sericin enhances the developmental competence of heat-stressed bovine embryos. Mol. Reprod. Dev. 2018, 85, 696-708. [CrossRef] [PubMed]

26. Sakatani, M.; Kobayashi, S.; Takahashi, M. Effects of heat shock on in vitro development and intracellular oxidative state of bovine preimplantation embryos. Mol. Reprod. Dev. 2004, 67, 77-82. [CrossRef] [PubMed]

27. Rosenkrans, C.F., Jr.; Zeng, G.Q.; GT, M.C.; Schoff, P.K.; First, N.L. Development of bovine embryos in vitro as affected by energy substrates. Biol. Reprod. 1993, 49, 459-462. [CrossRef]

28. Aboelenain, M.; Kawahara, M.; Balboula, A.Z.; Montasser Ael, M.; Zaabel, S.M.; Okuda, K.; Takahashi, M. Status of autophagy, lysosome activity and apoptosis during corpus luteum regression in cattle. J. Reprod. Dev. 2015, 61, 229-236. [CrossRef] [PubMed]

29. Wang, F.; Tian, X.; Zhou, Y.; Tan, D.; Zhu, S.; Dai, Y.; Liu, G. Melatonin improves the quality of in vitro produced (IVP) bovine embryos: Implications for blastocyst development, cryotolerance, and modifications of relevant gene expression. PLoS ONE 2014, 9, e93641. [CrossRef] [PubMed]

30. Miranda, M.S.; Nascimento, H.S.; Costa, M.P.; Costa, N.N.; Brito, K.N.; Lopes, C.T.; Santos, S.S.; Cordeiro, M.S.; Ohashi, O.M. Increasing of blastocyst rate and gene expression in co-culture of bovine embryos with adult adipose tissue-derived mesenchymal stem cells. J. Assist. Reprod. Genet. 2016, 33, 1395-1403. [CrossRef]

31. Remiao, M.H.; Lucas, C.G.; Domingues, W.B.; Silveira, T.; Barther, N.N.; Komninou, E.R.; Basso, A.C.; Jornada, D.S.; Beck, R.C.R.; Pohlmann, A.R.; et al. Melatonin delivery by nanocapsules during in vitro bovine oocyte maturation decreased the reactive oxygen species of oocytes and embryos. Reprod. Toxicol. 2016, 63, 70-81. [CrossRef]

32. Wrenzycki, C.; Herrmann, D.; Niemann, H. Timing of blastocyst expansion affects spatial messenger RNA expression patterns of genes in bovine blastocysts produced in vitro. Biol. Reprod. 2003, 68, 2073-2080. [CrossRef] [PubMed]

33. Bols, P.E.J.; Jorssen, E.P.A.; Goovaerts, I.G.F.; Langbeen, A.; Leroy, J.L.M.R. High throughput non-invasive oocyte quality assessment: The search continues. Anim. Reprod. 2012, 9, 420-425.

34. Merton, J.S.; Knijn, H.M.; Flapper, H.; Dotinga, F.; Roelen, B.A.; Vos, P.L.; Mullaart, E. Cysteamine supplementation during in vitro maturation of slaughterhouse- and opu-derived bovine oocytes improves embryonic development without affecting cryotolerance, pregnancy rate, and calf characteristics. Theriogenology 2013, 80, 365-371. [CrossRef] [PubMed]

35. Bossy-Wetzel, E.; Newmeyer, D.D.; Green, D.R. Mitochondrial cytochrome c release in apoptosis occurs upstream of DEVD-specific caspase activation and independently of mitochondrial transmembrane depolarization. EMBO J. 1998, 17, 37-49. [CrossRef] [PubMed]

36. Li, P.; Nijhawan, D.; Budihardjo, I.; Srinivasula, S.M.; Ahmad, M.; Alnemri, E.S.; Wang, X. Cytochrome c and dATP-dependent formation of Apaf-1/caspase-9 complex initiates an apoptotic protease cascade. Cell 1997, 91, 479-489. [CrossRef]

37. de Castro, M.A.; Bunt, G.; Wouters, F.S. Cathepsin B launches an apoptotic exit effort upon cell death-associated disruption of lysosomes. Cell Death Discov. 2016, 2, 16012. [CrossRef] 